\title{
Impact and indication of early systemic corticosteroids for very severe community-acquired pneumonia
}

This article was published in the following Dove Press journal:

International Journal of General Medicine

19 August 2013

Number of times this article has been viewed

\section{Motoi Ugajin \\ Kenichi Yamaki \\ Natsuko Hirasawa \\ Takanori Kobayashi \\ Takeo Yagi}

Department of Respiratory Medicine, Ichinomiya-Nishi Hospital, Ichinomiya City, Aichi Prefecture, Japan
Correspondence: Motoi Ugajin

Department of Respiratory

Medicine, Ichinomiya-Nishi

Hospital, I Hira, Kaimei,

Ichinomiya City, 494-000I, Japan

Tel +8I 586480077

Fax +8I 586480038

Email ugarin200I@yahoo.co.jp
Background: The efficacy of systemic corticosteroids in community-acquired pneumonia (CAP) has not yet been confirmed. We prospectively investigated the clinical features of patients treated with early adjunctive systemic corticosteroids and its clinical impact in very severe CAP.

Methods: One hundred and one consecutive CAP patients having a pneumonia severity index of $>130$ points were enrolled from August 2010 through February 2013. Early adjunctive systemic corticosteroids were defined as administration of systemic corticosteroids equivalent to prednisone of $\geq 20 \mathrm{mg} /$ day added to initial antibiotics. The multivariate analysis was performed to evaluate the independent factors associated with mortality.

Results: Thirty-two patients $(31.7 \%)$ died within 28 days of admission. Early adjunctive systemic corticosteroids were administered in 30 patients $(29.7 \%)$, who more frequently had alteration of mental status, serious respiratory failure, or underlying lung diseases and received fluoroquinolones as initial antibiotics. In most patients treated with early adjunctive systemic corticosteroids, the dosage was less than $60 \mathrm{mg}$ /day of an equivalent to prednisone by bolus intravenous infusion for a period shorter than 8 days. The occurrence of adverse events did not differ between the groups. Factors independently associated with mortality were blood urea nitrogen (hazard ratio [HR] 1.02, 95\% confidence interval [CI] 1.00-1.04), serum albumin (HR $0.44,95 \%$ CI $0.22-0.86$ ), a requirement for intensive care (HR 4.93, 95\% CI 1.75-13.87), and the therapy with early adjunctive systemic corticosteroids (HR $0.29,95 \%$ CI $0.11-0.81$ ).

Conclusion: Early adjunctive systemic corticosteroids may have an effect to reduce the mortality in very severe CAP, although a larger-scale study is necessary.

Keywords: pneumonia severity index, initial antibiotics, mortality, intensive care, communityacquired pneumonia, corticosteroids

\section{Introduction}

Community-acquired pneumonia (CAP) remains a serious illness and a major cause of death. Former studies have shown that in patients with CAP, systemic inflammatory responses lead to poor clinical outcomes. ${ }^{1,2}$ Therefore, attenuating systemic inflammatory responses is occasionally attempted in severe CAP. Corticosteroids are well known as anti-inflammatory agents and act at the genomic level.

In severe sepsis and septic shock, there is growing evidence that low-dose systemic corticosteroids may contribute to favorable clinical outcomes. ${ }^{3,4}$ However, in CAP, the efficacy of systemic corticosteroids added to antibiotic therapy has not yet been confirmed. In a retrospective study, Garcia-Vidal et al reported that the administration of systemic corticosteroids contributed to the reduction of mortality in severe CAP. ${ }^{5}$ In contrast, the randomized, double-blind, placebo-controlled study produced by Snijders 
et al showed no beneficial effects of adjunctive corticosteroids in hospitalized CAP patients. ${ }^{6}$

Most of the previous placebo-controlled interventional CAP studies included a limited number of critically ill patients. ${ }^{6-9}$ Therefore, the impact of adjunctive systemic corticosteroids on the prognosis of CAP has not yet been revealed. In current clinical practice, systemic corticosteroids are often added to the initial administration of antibiotics in some cases of very severe CAP, depending on the discretion of each pulmonologist.

In this single-center, prospective, and observational study, we investigated the clinical features of patients treated with early adjunctive systemic corticosteroids and impact of early adjunctive systemic corticosteroids on clinical outcomes in very severe CAP.

\section{Materials and methods}

\section{Patients}

Consecutive patients admitted to the Ichinomiya-Nishi hospital (a 400-bed teaching hospital in Ichinomiya City, Aichi, Japan) because of CAP, from August 2010 through February 2013, who had a pneumonia severity index (PSI) of $>130$ points (class 5$)^{10}$ on admission, were enrolled in this study. CAP was diagnosed in patients aged $\geq 18$ years who were admitted from the community or a nursing home, had not been hospitalized in the 90 days before the start of the study, did not have any antibiotic exposure during the 14 days prior to enrollment, presented with a new radiographic infiltrate, and who showed at least two compatible clinical symptoms (body temperature $>38^{\circ} \mathrm{C}$, productive cough, chest pain, shortness of breath, or crackles on auscultation). Patients were excluded if they were chronically immunosuppressed (chemotherapy, human immunodeficiency virus infection, therapy with corticosteroids, or other immunosuppressive agents).

Informed consent was obtained from all patients, according to the hospital's guidelines. This study protocol and consent procedure followed the statements of the Declaration of Helsinki, and was approved by the ethics committee of our hospital, called the Research Ethics Review Committee of Ichinomiya-Nishi Hospital (Study Number 25011).

\section{Methods and endpoints}

Calculation of PSI, collection of venous blood samples, arterial blood gas analysis, microbiological sputum examination, and urinary antigen tests for Streptococcus pneumoniae (Alere BinaxNOW ${ }^{\circledR}$ S pneumoniae Antigen Card; Alere Inc, Waltham, MA, USA) and Legionella pneumophila serogroup 1 (Alere BinaxNOW ${ }^{\circledR}$ Legionella Urinary Antigen
Card; Alere Inc) were performed on admission for all CAP patients. Measurements of blood counts and levels of serum biochemical markers (C-reactive protein [CRP], blood urea nitrogen, albumin, glucose, sodium, and creatinine) were performed immediately after blood sampling. Serum CRP level was measured using a latex agglutination assay (N-Assay LA CRP-S, Nittobo Medical, Tokyo, Japan). Other biochemical markers were assayed using standard methods. Causative pathogens were diagnosed with the finding of $3+$ growth in the sputum culture or the presence of antigen in urine.

Coexisting illnesses (heart failure, diabetes mellitus, cerebrovascular diseases, neoplastic diseases, chronic kidney diseases, advanced liver diseases, chronic obstructive pulmonary disease [COPD], and other lung diseases) were assessed by the treating pulmonologists.

Performance status before admission was evaluated according to the European Cooperative Oncology Group score. ${ }^{11}$ The grades were defined as follows: grade $0=$ fully active, able to carry on all predisease performance without restriction; grade 1 = restricted in physically strenuous activity but ambulatory and able to carry out work of a light or sedentary nature; grade 2 = ambulatory and capable of all self-care but unable to carry out any work activity, up and about more than $50 \%$ of working hours; grade $3=$ capable of only limited self-care, confined to bed or chair more than $50 \%$ of working hours; and grade $4=$ completely disabled, cannot carry on any self-care, totally confined to bed or chair.

The choice of antibiotic regimen was made according to the national guidelines proposed by the Japanese Respiratory Society. ${ }^{12}$ The administration of systemic corticosteroids was left to the discretion of each treating pulmonologist. Treatment with early adjunctive systemic corticosteroids was defined as administration of dosages equivalent to prednisone of $\geq 20 \mathrm{mg} /$ day, which is considered as a "stress dose" of systemic corticosteroids for pneumonia, ${ }^{13}$ added to the initial intravenous antibiotic medication.

The primary endpoint of this study was mortality within 28 days of admission. The secondary endpoints were requirement for intensive care and occurrence of adverse events. Requirement for intensive care was defined as the use of mechanical ventilation or vasopressors against shock. Adverse events were defined as hyperglycemia with requirement for additional glucose-lowering therapy, confusion, nosocomial infection, or gastrointestinal bleeding.

\section{Statistical analysis}

The data were expressed as numbers or medians (25th-75th percentile range). The differences between the two groups 
were tested using the nonparametric Mann-Whitney $U$ test for continuous variables and Fisher's exact test for categorical variables. Survival curves from admission were plotted using the Kaplan-Meier method, and the comparison between two curves was performed using the logrank test. To investigate the independent factors associated with mortality, multivariate analysis was performed using the Cox proportional hazard model. The variables incorporated in the multivariate analysis were the factors significantly associated with mortality at the 0.20 level in univariate analysis. The results were expressed as hazard ratio (HR) and $95 \%$ confidence interval (CI). A two-tailed probability value $<0.05$ was considered to be statistically significant.

\section{Results}

\section{Patient population}

During the study period, a total of 469 patients were admitted because of CAP. Of these, 103 had a PSI score of $>130$ points on admission. Two patients were excluded because of immunosuppression. Thus finally, 101 patients having $>130$ points of PSI on admission were enrolled in this study (Figure 1).

The baseline characteristics of enrolled patients are shown in Table 1. No one had advanced liver disease, while eight patients $(7.9 \%)$ had chronic kidney disease. Fourteen patients $(13.9 \%)$ had underlying lung diseases, including COPD $(n=11)$, bronchial asthma $(n=2)$, and chronic interstitial pneumonia $(\mathrm{n}=1)$. Thirty-two patients $(31.7 \%)$ died within 28 days of admission, and 45 patients (44.6\%) needed intensive care. Causative pathogens were detected

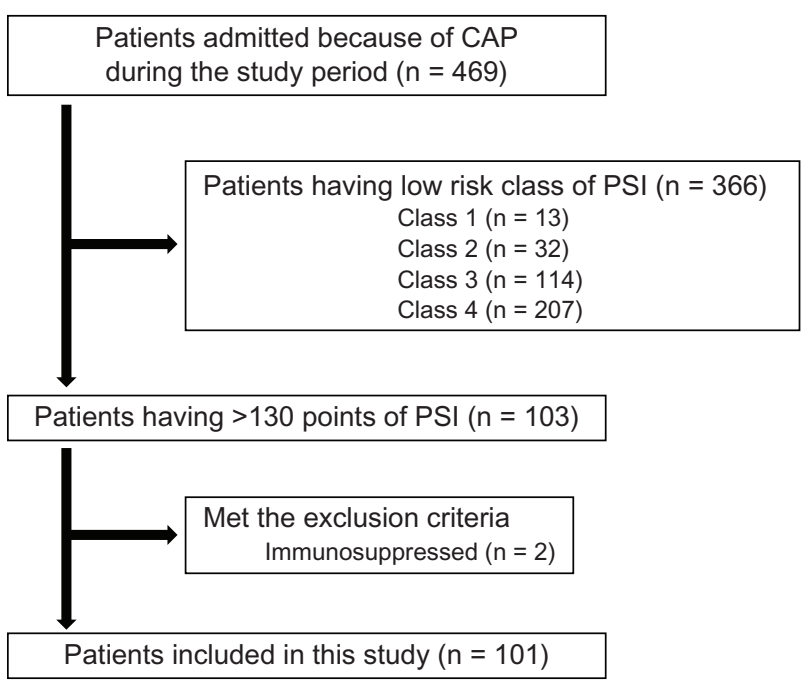

Figure I Flow diagram explaining recruitment of study population. Abbreviations: CAP, community-acquired pneumonia; PSI, pneumonia severity index.
Table I Baseline characteristics of enrolled patients

\begin{tabular}{|c|c|}
\hline Characteristics & Values \\
\hline Number & 101 \\
\hline Age, years & $86(8 I-9 \mid)$ \\
\hline Male patients & $66(65.3)$ \\
\hline From nursing home & $57(56.4)$ \\
\hline Performance status & $3(2-3)$ \\
\hline \multicolumn{2}{|l|}{ Physical findings on admission } \\
\hline Systolic blood pressure $<90 \mathrm{mmHg}$ & $22(21.8)$ \\
\hline Altered mental status $\dagger$ & $53(52.5)$ \\
\hline Requirement for high-flow oxygen & $5 \mathrm{I}(50.5)$ \\
\hline Heart rate, per minute & $104(86-116)$ \\
\hline \multicolumn{2}{|l|}{ Laboratory findings on admission } \\
\hline C-reactive protein, $\mathrm{mg} / \mathrm{dL}$ & $12.52(5.96-23.55)$ \\
\hline Leukocyte count, $10^{9}$ cells $/ \mathrm{L}$ & II.7 (8.6-I4.2) \\
\hline Blood urea nitrogen, mg/dL & $31.8(21.3-43.3)$ \\
\hline Albumin, g/dL & $3.1(2.6-3.5)$ \\
\hline Sodium, mEq/L & $138(132-143)$ \\
\hline Glucose, mg/dL & $133(109-174)$ \\
\hline Creatinine, $\mathrm{mg} / \mathrm{dL}$ & $1.01(0.66-1.51)$ \\
\hline Hematocrit, \% & $35.4(30.3-39.2)$ \\
\hline $\mathrm{pH}$ of arterial blood & $7.4 \mathrm{I}(7.33-7.47)$ \\
\hline $\mathrm{PaCO}_{2}, \mathrm{mmHg}$ & $41.4(34.1-48.0)$ \\
\hline \multicolumn{2}{|l|}{ Radiographic findings on admission } \\
\hline Bilateral infiltrates & $72(7 \mid .3)$ \\
\hline Pleural effusion & $38(37.6)$ \\
\hline \multicolumn{2}{|l|}{ Coexisting illnesses } \\
\hline Heart failure & $25(24.8)$ \\
\hline Diabetes mellitus & $16(15.8)$ \\
\hline Cerebrovascular diseases & $42(41.6)$ \\
\hline Neoplastic diseases & $9(8.9)$ \\
\hline Chronic kidney diseases & $8(7.9)$ \\
\hline COPD & II (10.9) \\
\hline Other lung diseases & $3(3.0)$ \\
\hline Pneumonia severity index & $152(139-179)$ \\
\hline \multicolumn{2}{|l|}{ Initial antibiotic regimens } \\
\hline Antipseudomonal beta-lactams & $81(80.2)$ \\
\hline Fluoroquinolones & $14(13.9)$ \\
\hline Tetracyclines & $25(24.8)$ \\
\hline Clindamycin & $9(8.9)$ \\
\hline Early adjunctive systemic steroids & $30(29.7)$ \\
\hline \multicolumn{2}{|l|}{ Clinical outcomes } \\
\hline Mortality within 28 days of admission & $32(31.7)$ \\
\hline Requirement for intensive care & $45(44.6)$ \\
\hline
\end{tabular}

Notes: Data are expressed as number (\%) or median (25th-75th percentile). tDefined as a state of awareness that differed from the normal awareness of each person; ¥defined as a necessity of oxygen inhalation with mask or mechanical ventilation in order to keep arterial oxygen saturation $\geq 90 \%$.

Abbreviations: COPD, chronic obstructive pulmonary disease; $\mathrm{PaCO}_{2}$, partial pressure of carbon dioxide in arterial blood.

in 56 patients $(55.4 \%)$ and are listed in Table 2 . The most frequently detected pathogen was $S$. pneumoniae ( $\mathrm{n}=17,16.8 \%)$.

\section{Indication for and impact of early adjunctive systemic corticosteroids}

Thirty patients (29.7\%) were administered systemic corticosteroids added to their initial antibiotic medication. 
Table 2 Detected pathogens

\begin{tabular}{ll}
\hline Microorganism & Number \\
\hline Streptococcus pneumoniae & $17(16.8)$ \\
Klebsiella pneumoniae & $9(8.9)$ \\
MRSA & $9(8.9)$ \\
Staphylococcus spp. & $8(7.9)$ \\
Pseudomonas aeruginosa & $6(5.9)$ \\
Escherichia coli & $2(2.0)$ \\
Proteus mirabilis & $2(2.0)$ \\
Acinetobacter baumannii & $1(1.0)$ \\
Enterococcus spp. & $\mathrm{I}(1.0)$ \\
Serratia marcescens & $\mathrm{I}(1.0)$ \\
Unknown & $45(44.6)$ \\
\hline
\end{tabular}

Note: Data are expressed as number (\%).

Abbreviation: MRSA, methicillin-resistant Staphylococcus aureus.

The dosages of adjunctive systemic corticosteroids are listed in Table 3. The median dosage of early adjunctive systemic corticosteroids was $50 \mathrm{mg} /$ day (30-50 mg/day) of an equivalent to prednisone. Most patients treated with early adjunctive systemic corticosteroids received a bolus intravenous infusion for a period shorter than 8 days.

The characteristics of patients treated with and without early adjunctive systemic corticosteroids are shown in Table 4. Of physical findings on admission, the patients treated with early adjunctive systemic corticosteroids were more likely to have an alteration of mental status ( $80.0 \%$ versus $40.8 \%)$ $(P<0.001)$ and requirement for high flow oxygen inhalation (66.7\% versus $43.7 \%)(P=0.049)$ than were those without early corticosteroids. Of laboratory findings, the patients treated with early adjunctive systemic corticosteroids were more likely to have lower leukocyte counts $\left(10.4 \times 10^{9}\right.$ cells $/ \mathrm{L}$ versus $12.1 \times 10^{9}$ cells/L) $(P=0.039)$, lower sodium levels $(137 \mathrm{mEq} / \mathrm{L}$ versus $139 \mathrm{mEq} / \mathrm{L})(P=0.031)$, and higher

Table 3 Dosage and duration of early systemic corticosteroids

\begin{tabular}{ll}
\hline & Number \\
\hline Corticosteroids & 17 \\
Methylprednisolone & 12 \\
Prednisolone & 1 \\
Dexamethasone & \\
Dosage (equivalent to prednisone) & 25 \\
$20-60$ mg/day & 5 \\
$\geq 61$ mg/day & \\
Dosing duration & 6 \\
3 days & 18 \\
$4-7$ days & 6 \\
$\geq 8$ days & \\
Dosing methods & 0 \\
Orally & 30 \\
Intravenously & 29 \\
Bolus infusion & 1 \\
\hline
\end{tabular}

albumin levels $(3.3 \mathrm{~g} / \mathrm{dL}$ versus $3.0 \mathrm{~g} / \mathrm{dL})(P=0.003)$. Of coexisting illnesses, the patients treated with early adjunctive systemic corticosteroids were more likely to have COPD (26.7\% versus $4.2 \%)(P=0.002)$ and other lung diseases $(10.0 \%$ versus 0$)(P=0.024)$ and less likely to have cerebrovascular diseases $(23.3 \%$ versus $49.3 \%)(P=0.017)$. Of initial antibiotic regimens, the patients treated with early adjunctive systemic corticosteroids were more likely to receive fluoroquinolones $(26.7 \%$ versus $8.5 \%)(P=0.025)$. Of radiographic and microbiological findings, no significant differences were observed between the patients with and without early adjunctive systemic corticosteroids.

Concerning the clinical outcomes, mortality and the requirement for intensive care did not differ significantly between the patients treated with and without early adjunctive systemic corticosteroids.

\section{Adverse events}

The adverse events of patients treated with and without early adjunctive systemic corticosteroids are shown in Table 5. There were no significant differences of any adverse event between the groups. Septic shock induced by urinary tract infection occurred in one patient treated without early corticosteroids after 15 days of admission, while the other nosocomial infections were recurrence of pneumonia. Fatal gastrointestinal bleeding occurred in one patient treated without early corticosteroids after 10 days of admission.

\section{Factors associated with mortality}

A comparison of the characteristics of deceased and surviving patients is shown in Table 6 . The deceased patients were more likely to have needed intensive care $(78.1 \%$ versus $29.0 \%)(P<0.001)$ than were the surviving patients. Of laboratory findings, the deceased patients were more likely to have higher CRP levels $(18.78 \mathrm{mg} / \mathrm{dL}$ versus $10.79 \mathrm{mg} / \mathrm{dL})(P=0.017)$, higher blood urea nitrogen levels (39.8 $\mathrm{mg} / \mathrm{dL}$ versus $31.0 \mathrm{mg} / \mathrm{dL})(P=0.016)$, and lower albumin levels $(2.9 \mathrm{~g} / \mathrm{dL}$ versus $3.2 \mathrm{~g} / \mathrm{dL})(P=0.005)$. Of microbiological findings, the deceased patients were more likely to have an etiology of methicillin-resistant Staphylococcus aureus $(18.8 \%$ versus $4.3 \%)(P=0.027)$. Of initial antibiotic regimens, the deceased patients were more likely to receive antipseudomonal beta-lactam agents (93.8\% versus $73.9 \%)(P=0.03)$. Of physical findings, radiographic findings, and coexisting illnesses, no significant differences were observed between the deceased and surviving patients. 
Table 4 Characteristics between patients with and without early systemic steroids

\begin{tabular}{|c|c|c|c|}
\hline & Early systemic steroids & Without early steroids & $P$-value \\
\hline Number & 30 & 71 & \\
\hline Age, years & $85(80-90)$ & $86(81-92)$ & 0.517 \\
\hline Male patients & $22(73.3)$ & $44(62.0)$ & 0.361 \\
\hline From nursing home & $13(43.3)$ & $44(62.0)$ & 0.124 \\
\hline Performance status & $3(I-3)$ & $3(2-3)$ & 0.495 \\
\hline \multicolumn{4}{|l|}{ Physical findings on admission } \\
\hline Systolic blood pressure $<90 \mathrm{mmHg}$ & $10(33.3)$ & $12(16.9)$ & 0.111 \\
\hline Altered mental status ${ }^{\dagger}$ & $24(80.0)$ & $29(40.8)$ & $<0.001$ \\
\hline Requirement for high-flow oxygen & $20(66.7)$ & 31 (43.7) & 0.049 \\
\hline Heart rate, per minute & $111(95-123)$ & $100(83-113)$ & 0.096 \\
\hline \multicolumn{4}{|l|}{ Laboratory findings on admission } \\
\hline C-reactive protein, $\mathrm{mg} / \mathrm{dL}$ & $11.65(5.16-23.18)$ & $13.16(6.24-23.46)$ & 0.815 \\
\hline Leukocyte count, $10^{\circ}$ cells/L & $10.4(6.4-12.7)$ & $12.1(9.4-16.8)$ & 0.039 \\
\hline Blood urea nitrogen, mg/dL & $32.8(25.8-40.7)$ & $31.5(18.9-43.8)$ & 0.499 \\
\hline Albumin, g/dL & $3.3(3.1-3.7)$ & $3.0(2.6-3.4)$ & 0.003 \\
\hline Sodium, mEq/L & $137(|29-| 40)$ & $139(134-145)$ & 0.031 \\
\hline Glucose, mg/dL & $142(116-155)$ & $132(106-178)$ & 0.864 \\
\hline Creatinine, $\mathrm{mg} / \mathrm{dL}$ & $1.06(0.75-1.91)$ & $0.96(0.63-1.38)$ & 0.276 \\
\hline Hematocrit, \% & $37.1(32.7-40.4)$ & $35.1(29.3-38.7)$ & 0.089 \\
\hline $\mathrm{pH}$ of arterial blood & $7.37(7.29-7.46)$ & $7.43(7.34-7.48)$ & 0.126 \\
\hline $\mathrm{PaCO}_{2}, \mathrm{mmHg}$ & $39.4(33.9-48.2)$ & $41.7(34.3-47.8)$ & 0.854 \\
\hline \multicolumn{4}{|l|}{ Radiographic findings on admission } \\
\hline Bilateral infiltrates & $24(80.0)$ & $48(67.6)$ & 0.238 \\
\hline Pleural effusion & $9(30.0)$ & $29(40.8)$ & 0.372 \\
\hline \multicolumn{4}{|l|}{ Coexisting illnesses } \\
\hline Heart failure & $6(20.0)$ & $19(26.8)$ & 0.616 \\
\hline Diabetes mellitus & $6(20.0)$ & $10(14.1)$ & 0.552 \\
\hline Cerebrovascular diseases & $7(23.3)$ & $35(49.3)$ & 0.017 \\
\hline Neoplastic diseases & $2(6.7)$ & $7(9.9)$ & 0.722 \\
\hline Chronic kidney diseases & $2(6.7)$ & $6(8.5)$ & $>0.999$ \\
\hline COPD & $8(26.7)$ & $3(4.2)$ & 0.002 \\
\hline Other lung diseases & $3(10.0)$ & 0 & 0.024 \\
\hline Pneumonia severity index & $149(|4|-179)$ & $154(135-175)$ & 0.629 \\
\hline Identification of pathogens & $20(66.7)$ & $36(50.7)$ & 0.189 \\
\hline Streptococcus pneumoniae & $7(23.3)$ & $10(14.1)$ & 0.26 \\
\hline Klebsiella pneumoniae & $5(16.7)$ & $4(5.6)$ & 0.121 \\
\hline MRSA & $3(10.0)$ & $6(8.5)$ & $>0.999$ \\
\hline \multicolumn{4}{|l|}{ Initial antibiotic regimens } \\
\hline Antipseudomonal beta-lactams & $24(80.0)$ & $57(80.3)$ & $>0.999$ \\
\hline Fluoroquinolones & $8(26.7)$ & $6(8.5)$ & 0.025 \\
\hline Tetracyclines & $8(26.7)$ & $17(23.9)$ & 0.804 \\
\hline Clindamycin & $\mathrm{I}(3.3)$ & $8(11.3)$ & 0.274 \\
\hline \multicolumn{4}{|l|}{ Clinical outcomes } \\
\hline Mortality within 28 days of admission & $6(20.0)$ & $26(36.6)$ & 0.159 \\
\hline Requirement for intensive care & $16(53.3)$ & $29(40.8)$ & 0.279 \\
\hline
\end{tabular}

Notes: Data are expressed as number (\%) or median (25th-75th percentile). 'Defined as a state of awareness that differed from the normal awareness of each person; ₹defined as a necessity of oxygen inhalation with mask or mechanical ventilation in order to keep arterial oxygen saturation $\geq 90 \%$.

Abbreviations: COPD, chronic obstructive pulmonary disease; MRSA, methicillin-resistant Staphylococcus aureus; PaCO, partial pressure of carbon dioxide in arterial blood.

The Kaplan-Meier survival curves for mortality within 28 days of admission did not differ significantly between the patients treated with and without early adjunctive systemic corticosteroids $(P=0.098)$ (Figure 2).

The results of multivariate analysis for mortality are shown in Table 7. Factors independently associated with mortality were blood urea nitrogen (HR 1.02, 95\% CI 1.00-1.04) ( $P=0.013)$, serum albumin level (HR 0.44, 95\% CI 0.22-0.86) $(P=0.017)$, a requirement for intensive care (HR 4.93, 95\% CI 1.75-13.87) $(P=0.003)$, and the therapy with early adjunctive systemic corticosteroids (HR $0.29,95 \%$ CI $0.11-0.81)(P=0.018)$. 
Table 5 Adverse events between patients with and without early systemic corticosteroids

\begin{tabular}{llll}
\hline & $\begin{array}{l}\text { Early systemic } \\
\text { steroids } \\
(\mathbf{n}=\mathbf{3 0})\end{array}$ & $\begin{array}{l}\text { Without early } \\
\text { steroids } \\
(\mathbf{n}=\mathbf{7 1})\end{array}$ & P-value \\
\hline $\begin{array}{l}\text { Hyperglycemia } \\
\text { with additional }\end{array}$ & $2(6.7)$ & $5(7.0)$ & $>0.999$ \\
$\begin{array}{l}\text { intervention } \\
\begin{array}{l}\text { Confusion } \\
\text { Nosocomial }\end{array}\end{array}$ & $6(20.0)$ & $6(8.5)$ & 0.174 \\
$\begin{array}{l}\text { infection } \\
\text { Gastrointestinal } \\
\text { bleeding }\end{array}$ & 0 & $5(7.0)$ & $>0.999$ \\
\hline Note: & $2(2.8)$ & $>0.999$ \\
\hline
\end{tabular}

Note: Data are expressed as number (\%).

\section{Discussion}

The present study in very severe CAP showed that (1) the addition of systemic corticosteroids to initial antibiotics was more frequently observed in patients having alteration of mental status, serious respiratory failure or underlying lung diseases, and receiving fluoroquinolones as initial antibiotics; (2) the dosage of additional (to initial antibiotics) systemic corticosteroids was less than $60 \mathrm{mg}$ /day of an equivalent to prednisone by bolus intravenous infusion for a period shorter than 8 days in most patients; (3) the occurrence of adverse events did not differ between the patients treated with and without early adjunctive systemic corticosteroids; and (4) the early adjunctive systemic corticosteroid was an independent protective factor for mortality.

Systemic inflammatory responses brought about by severe pneumonia cause critical conditions, such as respiratory failure and hypotension. ${ }^{14,15}$ Corticosteroids inhibit the expression and action of many cytokines involved in inflammatory responses by binding to their specific receptors, which are located in the cytoplasm of nearly all human cells. ${ }^{16}$ Therefore, systemic corticosteroids can suppress inflammatory responses in specific tissues as well as in the whole body. However, not many CAP studies have shown that adjunctive systemic corticosteroids reduce the risk of mortality. ${ }^{6-9,17}$ A recent meta-analysis showed that the addition of systemic corticosteroids for treatment of pneumonia accelerated the resolution of symptoms but did not reduce the mortality. ${ }^{18}$ To our knowledge, only two CAP studies have shown the efficacy of systemic corticosteroids for reducing mortality. ${ }^{5,19}$ In order to assess the influence of adjunctive systemic corticosteroids on mortality, it is necessary to study critically ill CAP patients. In fact, in clinical practice, the administration of adjunctive systemic corticosteroids is taken into consideration for critically ill CAP patients. However, most of the earlier CAP studies included patients with a mild to moderate severity of illness. In the present study, we confined our study cohort to critically ill patients, as per PSI, which is regarded as a reliable severity indicator of CAP throughout the world. ${ }^{20-22}$ This may be one of the reasons why our study showed favorable efficacy of systemic corticosteroids in reducing the risk of mortality in CAP patients.

It is not clear whether continuous or bolus infusion of corticosteroids is more appropriate for critically ill patients. Confalonieri et $\mathrm{al}^{19}$ reported that the continuous infusion of hydrocortisone for severe CAP contributed to favorable clinical outcomes. ${ }^{19}$ In contrast, Mikami et al showed that the bolus infusion of prednisolone for moderate to severe CAP contributed to prompt resolution of clinical symptoms. ${ }^{9}$ In patients with septic shock, a prospective, randomized study produced by Loisa et al has shown that there were no differences in mortality and vasopressor requirements of patients treated with continuous corticosteroid infusion and those treated with bolus infusion. ${ }^{23}$ Similarly, a randomized doubleblinded trial on ulcerative colitis showed that continuous corticosteroid infusion was not superior to bolus infusion in terms of efficacy and safety. ${ }^{24}$ In the present study, systemic corticosteroids were administered by bolus infusion to all patients except one. Our study may suggest that the bolus infusion of corticosteroids is appropriate for treating critically ill patients.

Systemic corticosteroids have several undesirable clinical effects, such as immunosuppression, hyperglycemia, and changes of mental condition. These adverse events often make patient care difficult. ${ }^{25-27}$ Nevertheless, there are few reports showing severe complications associated with adjunctive systemic corticosteroids in patients with CAP. In their CAP study, Meijvis et al documented that hyperglycemia was more common in patients treated with dexamethasone therapy than in those treated without dexamethasone, but the requirement for additional glucose-lowering therapy did not differ between the groups. ${ }^{8}$ Similarly, in the present CAP study, the early adjunctive systemic corticosteroids did not bring more adverse events compared with the therapy without early corticosteroids. It is well known that the incidence of significant side effects caused by systemic corticosteroids increases with the dose and duration of administration. ${ }^{28}$ Low-dose and short-term systemic corticosteroids are administered in most patients with CAP, including the patients in the present study. This type of treatment can be associated with safety of adjunctive systemic corticosteroids in patients with CAP.

We should mention that our current study has several limitations. First, our present study was not a placebo-controlled 
Table 6 Characteristics between deceased and surviving patients

\begin{tabular}{|c|c|c|c|}
\hline & Deceased & Surviving & $P$-value \\
\hline Number & 32 & 69 & \\
\hline Age, years & 84 (79-89) & $86(82-92)$ & 0.449 \\
\hline Male patients & $21(65.6)$ & $45(65.2)$ & $>0.999$ \\
\hline From nursing home & $18(56.3)$ & $39(56.5)$ & $>0.999$ \\
\hline Performance status & $3(2-3)$ & $3(2-3)$ & 0.647 \\
\hline \multicolumn{4}{|l|}{ Physical findings on admission } \\
\hline Systolic blood pressure $<90 \mathrm{mmHg}$ & $7(21.9)$ & $15(2 \mid .7)$ & $>0.999$ \\
\hline Altered mental status ${ }^{\dagger}$ & $20(62.5)$ & $33(47.8)$ & 0.202 \\
\hline Requirement for high-flow oxygen ${ }^{\ddagger}$ & $20(62.5)$ & $31(44.9)$ & 0.135 \\
\hline Heart rate, per minute & $105(94-119)$ & $104(84-116)$ & $0.57 \mid$ \\
\hline \multicolumn{4}{|l|}{ Laboratory findings on admission } \\
\hline C-reactive protein, $\mathrm{mg} / \mathrm{dL}$ & $18.78(8.60-26.55)$ & $10.79(4.29-19.86)$ & 0.017 \\
\hline Leukocyte count, $10^{9}$ cells/L & $10.3(8.7-14.2)$ & $11.9(8.3-14.2)$ & 0.748 \\
\hline Blood urea nitrogen, $\mathrm{mg} / \mathrm{dL}$ & $39.8(24.5-69.1)$ & $31.0(21.3-40.0)$ & 0.016 \\
\hline Albumin, $g / d L$ & $2.9(2.2-3.2)$ & $3.2(2.8-3.6)$ & 0.005 \\
\hline Sodium, $\mathrm{mEq} / \mathrm{L}$ & $140(133-148)$ & $138(|32-14|)$ & 0.168 \\
\hline Glucose, mg/dL & $118(104-17 \mid)$ & $138(110-174)$ & 0.184 \\
\hline Creatinine, $\mathrm{mg} / \mathrm{dL}$ & $1.19(0.69-2.04)$ & $0.96(0.62-1.30)$ & 0.161 \\
\hline Hematocrit, \% & $36.0(29.5-38.9)$ & $35.1(30.5-39.5)$ & 0.884 \\
\hline $\mathrm{pH}$ of arterial blood & $7.36(7.33-7.46)$ & $7.43(7.33-7.45)$ & 0.25 \\
\hline $\mathrm{PaCO}_{2}, \mathrm{mmHg}$ & $42.0(35.6-49.9)$ & $4 I .4(33.2-48.0)$ & 0.531 \\
\hline \multicolumn{4}{|l|}{ Radiographic findings on admission } \\
\hline Bilateral infiltrates & $26(81.3)$ & $46(66.7)$ & 0.16 \\
\hline Pleural effusion & $12(37.5)$ & $26(37.7)$ & $>0.999$ \\
\hline \multicolumn{4}{|l|}{ Coexisting illnesses } \\
\hline Heart failure & $7(21.9)$ & $18(26.1)$ & 0.805 \\
\hline Diabetes mellitus & $6(18.8)$ & $10(14.5)$ & 0.572 \\
\hline Cerebrovascular diseases & $12(37.5)$ & $30(43.5)$ & 0.666 \\
\hline Neoplastic diseases & $2(6.3)$ & $7(10.1)$ & 0.715 \\
\hline Chronic kidney diseases & $3(9.4)$ & $5(7.2)$ & 0.706 \\
\hline COPD & $3(9.4)$ & $8(11.6)$ & $>0.999$ \\
\hline Other lung diseases & $\mathrm{I}(3.1)$ & $2(2.9)$ & $>0.999$ \\
\hline Pneumonia severity index & $163(147-180)$ & $146(|36-17|)$ & 0.071 \\
\hline Identification of pathogens & $21(65.6)$ & $35(50.7)$ & 0.199 \\
\hline Streptococcus pneumoniae & $4(12.5)$ & $13(18.8)$ & 0.571 \\
\hline Klebsiella pneumoniae & $\mathrm{I}(3.1)$ & $8(11.6)$ & 0.266 \\
\hline MRSA & $6(18.8)$ & $3(4.3)$ & 0.027 \\
\hline \multicolumn{4}{|l|}{ Initial antibiotic regimens } \\
\hline Antipseudomonal beta-lactams & $30(93.8)$ & $51(73.9)$ & 0.03 \\
\hline Fluoroquinolones & $3(9.4)$ & II (I5.9) & 0.539 \\
\hline Tetracyclines & $9(28.1)$ & $16(23.2)$ & 0.625 \\
\hline Clindamycin & $2(6.3)$ & $7(10.1)$ & 0.715 \\
\hline Early adjunctive systemic steroids & $6(18.8)$ & $24(34.8)$ & 0.159 \\
\hline Requirement for intensive care & $25(78.1)$ & $20(29.0)$ & $<0.001$ \\
\hline
\end{tabular}

Notes: Data are expressed as number (\%) or median (25th-75th percentile). 'Defined as a state of awareness that differed from the normal awareness of each person; \#defined as a necessity of oxygen inhalation with mask or mechanical ventilation in order to keep arterial oxygen saturation $\geq 90 \%$.

Abbreviations: COPD, chronic obstructive pulmonary disease; MRSA, methicillin-resistant Staphylococcus aureus; $\mathrm{PaCO}_{2}$, partial pressure of carbon dioxide in arterial blood.

interventional study. Therefore, the dosage and term of systemic corticosteroids and the antibiotic regimen varied for each patient. However, most of our study cohort received low-dose and short-term systemic corticosteroids, in the same way as in former interventional CAP studies. Additionally, in order to reduce the influence of various confounders as much as possible, we performed the multivariate analysis for assessment of the factors associated with mortality. Second, this study cohort included a limited number of patients because it was a single-center observational study. To demonstrate the clinical impact of early adjunctive systemic corticosteroids for very severe CAP, further multicenter studies including a large number of patients with very severe CAP are needed. Third, adrenocortical function 


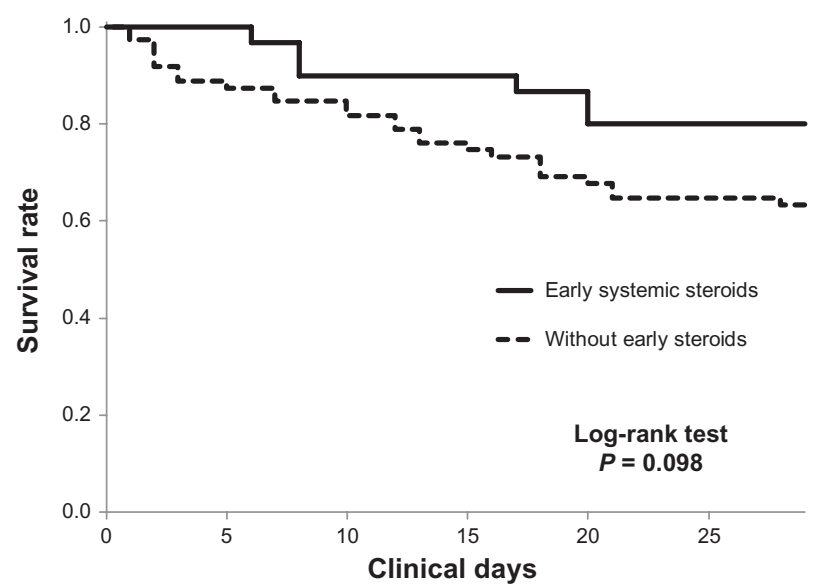

Figure 2 Kaplan-Meier survival curves in patients treated with and without early adjunctive systemic corticosteroids. No significant difference was observed between both groups $(P=0.098)$.

was not evaluated in our study. Although some former studies have shown that relative adrenal insufficiency has little influence on the clinical courses of CAP, $, 29,30$ we could not exclude the possibility that adjunctive systemic corticosteroids compensated for adrenal insufficiency. Finally, most patients in our study cohort were of advanced age. Therefore, the mortality rate in our present study may have been higher than that in other CAP studies. Although the age did not differ between deceased and surviving patients in our present study, additional studies including critically ill younger patients are

Table 7 Multivariate analysis for mortality within 28 days of admission

\begin{tabular}{|c|c|c|}
\hline & $\begin{array}{l}\text { Hazard ratio } \\
(95 \% \mathrm{CI})\end{array}$ & $P$-value \\
\hline \multicolumn{3}{|l|}{ Physical findings on admission } \\
\hline Requirement for high-flow oxygen ${ }^{\ddagger}$ & $1.95(0.63-6.01)$ & 0.246 \\
\hline \multicolumn{3}{|l|}{ Laboratory findings on admission } \\
\hline C-reactive protein & $0.99(0.96-1.03)$ & 0.69 \\
\hline Blood urea nitrogen & $1.02(1.00-1.04)$ & 0.013 \\
\hline Albumin & $0.44(0.22-0.86)$ & 0.017 \\
\hline Sodium & $0.99(0.95-1.02)$ & 0.44 \\
\hline Glucose & $0.99(0.99-1.00)$ & 0.053 \\
\hline Creatinine & $0.89(0.58-1.36)$ & 0.578 \\
\hline \multicolumn{3}{|l|}{ Radiographic findings on admission } \\
\hline Bilateral infiltrates & $1.55(0.48-5.05)$ & 0.466 \\
\hline Pneumonia severity index & $1.00(0.98-1.02)$ & 0.899 \\
\hline Identification of pathogens & $\mathrm{I} .34(0.54-3.34)$ & 0.527 \\
\hline MRSA & $2.92(0.72-11.83)$ & 0.133 \\
\hline \multicolumn{3}{|l|}{ Initial antibiotic regimens } \\
\hline Antipseudomonal beta-lactams & $1.39(0.30-6.46)$ & 0.674 \\
\hline Early adjunctive systemic steroids & $0.29(0.11-0.81)$ & 0.018 \\
\hline Requirement for intensive care & $4.93(1.75-13.87)$ & 0.003 \\
\hline
\end{tabular}

Note: 就位ed as a necessity of oxygen inhalation with mask or mechanical ventilation in order to keep arterial oxygen saturation $\geq 90 \%$.

Abbreviations: $\mathrm{Cl}$, confidence interval; MRSA, methicillin-resistant Staphylococcus aureus. needed in order to prove the clinical impact of early adjunctive systemic corticosteroids for very severe CAP.

In conclusion, early adjunctive systemic corticosteroids may be expected to have the efficacy to reduce the mortality in very severe CAP. We can consider the administration of systemic corticosteroids simultaneously with initial antibiotic medication in cases of very severe CAP, although a largerscale prospective study is necessary.

\section{Author contributions}

All authors contributed to the conception of the study and the data collection, and critically reviewed the manuscript. Dr Ugajin additionally performed the data analysis and wrote the manuscript, and Dr Yamaki also proofread the manuscript.

\section{Disclosure}

The authors report no conflicts of interest in this work.

\section{References}

1. Puren AJ, Feldman C, Savage N, Becker PJ, Smith C. Patterns of cytokine expression in community-acquired pneumonia. Chest. 1995; 107(5):1342-1349.

2. Montón C, Torres A, El-Ebiary M, Filella X, Xaubet A, de la Bellacasa JP. Cytokine expression in severe pneumonia: a bronchoalveolar lavage study. Crit Care Med. 1999;27(9):1745-1753.

3. Annane D, Bellissant E, Bollaert PE, et al. Corticosteroids in the treatment of severe sepsis and septic shock in adults: a systematic review. JAMA. 2009;301(22):2362-2375.

4. Sligl WI, Milner DA, Sundar S, Mphatswe W, Majumdar SR. Safety and efficacy of corticosteroids for the treatment of septic shock: A systematic review and meta-analysis. Clin Infect Dis. 2009;49(1):93-101.

5. Garcia-Vidal C, Calbo E, Pascual V, Ferrer C, Quintana S, Garau J. Effects of systemic steroids in patients with severe community-acquired pneumonia. Eur Respir J. 2007;30(5):951-956.

6. Snijders D, Daniels JM, de Graaff CS, van der Werf TS, Boersma WG. Efficacy of corticosteroids in community-acquired pneumonia: a randomized double-blinded clinical trial. Am J Respir Crit Care Med. 2010;181(9):975-982.

7. Fernández-Serrano S, Dorca J, Garcia-Vidal C, et al. Effect of corticosteroids on the clinical course of community-acquired pneumonia: a randomized controlled trial. Crit Care. 2011;15(2):R96.

8. Meijvis SC, Hardeman H, Remmelts HH, et al. Dexamethasone and length of hospital stay in patients with community-acquired pneumonia: a randomised, double-blind, placebo-controlled trial. Lancet. 2011;377(9782):2023-2030.

9. Mikami K, Suzuki M, Kitagawa H, et al. Efficacy of corticosteroids in the treatment of community-acquired pneumonia requiring hospitalization. Lung. 2007;185(5):249-255.

10. Fine MJ, Auble TE, Yealy DM, et al. A prediction rule to identify lowrisk patients with community-acquired pneumonia. $N$ Engl $J$ Med. 1997;336(4):243-250.

11. Oken MM, Creech RH, Tormey DC, et al. Toxicity and response criteria of the Eastern Cooperative Oncology Group. Am J Clin Oncol. 1982;5(6):649-655.

12. Miyashita N, Matsushima T, Oka M. Japanese Respiratory Society. The JRS guidelines for the management of community-acquired pneumonia in adults: an update and new recommendations. Intern Med. 2006;45(7):419-428. 
13. Jung $\mathrm{C}$, Inder WJ. Management of adrenal insufficiency during the stress of medical illness and surgery. Med J Aust. 2008;188(7):409-413.

14. Ware LB, Matthay MA. The acute respiratory distress syndrome. N Engl J Med. 2000;342:1334-1349.

15. Martínez R, Menéndez R, Reyes S, et al. Factors associated with inflammatory cytokine patterns in community-acquired pneumonia. Eur Respir J. 2011;37(2):393-399.

16. Sibila O, Agustí C, Torres A. Corticosteroids in severe pneumonia. Eur Respir J. 2008;32(2):259-264.

17. Marik P, Kraus P, Sribante J, Havlik I, Lipman J, Johnson DW. Hydrocortisone and tumor necrosis factor in severe community-acquired pneumonia. A randomized controlled study. Chest. 1993;104(2): 389-392.

18. Chen Y, Li K, Pu H, Wu T. Corticosteroids for pneumonia. Cochrane Database Syst Rev. 2011;16(3):CD007720.

19. Confalonieri M, Urbino R, Potena A, et al. Hydrocortisone infusion for severe community-acquired pneumonia: a preliminary randomized study. Am J Respir Crit Care Med. 2005;171(3):242-248.

20. Aujesky D, Auble TE, Yealy DM, et al. Prospective comparison of three validated prediction rules for prognosis in community-acquired pneumonia. Am J Med. 2005;118(4):384-392.

21. Valencia M, Badia JR, Cavalcanti M, et al. Pneumonia severity index class v patients with community-acquired pneumonia: characteristics, outcomes, and value of severity scores. Chest. 2007;132(2):515-522.

22. Ugajin M, Yamaki K, Iwamura N, Yagi T, Asano T. Blood urea nitrogen to serum albumin ratio independently predicts mortality and severity of community-acquired pneumonia. Int J Gen Med. 2012;5:583-589.

23. Loisa P, Parviainen I, Tenhunen J, Hovilehto S, Ruokonen E. Effect of mode of hydrocortisone administration on glycemic control in patients with septic shock: a prospective randomized trial. Crit Care. 2007;11(1):R21
24. Bossa F, Fiorella S, Caruso N, et al. Continuous infusion versus bolus administration of steroids in severe attacks of ulcerative colitis: a randomized, double-blind trial. Am J Gastroenterol. 2007;102(3): 601-608.

25. Steinberg KP, Hudson LD, Goodman RB, et al; National Heart, Lung, and Blood Institute Acute Respiratory Distress Syndrome (ARDS) Clinical Trials Network. Efficacy and safety of corticosteroids for persistent acute respiratory distress syndrome. $N$ Engl J Med. 2006;354(16): 1671-1684.

26. Brown ES, Chandler PA. Mood and cognitive changes during systemic corticosteroid therapy. Prim Care Companion J Clin Psychiatry. 2001;3(1):17-21.

27. Dixon WG, Suissa S, Hudson M. The association between systemic glucocorticoid therapy and the risk of infection in patients with rheumatoid arthritis: systematic review and meta-analyses. Arthritis Res Ther. 2011;13(4):R139.

28. Stanbury RM, Graham EM. Systemic corticosteroid therapy - side effects and their management. Br J Ophthalmol. 1998;82(6):704-708.

29. Salluh JI, Bozza FA, Soares M, et al. Adrenal response in severe community-acquired pneumonia: impact on outcomes and disease severity. Chest. 2008;134(5):947-954.

30. Kolditz M, Halank M, Schulte-Hubbert B, Höffken G. Adrenal function is related to prognosis in moderate community-acquired pneumonia. Eur Respir J. 2010;36(3):615-621.
International Journal of General Medicine

\section{Publish your work in this journal}

The International Journal of General Medicine is an international, peer-reviewed open-access journal that focuses on general and internal medicine, pathogenesis, epidemiology, diagnosis, monitoring and treatment protocols. The journal is characterized by the rapid reporting of reviews, original research and clinical studies across all disease areas.

\section{Dovepress}

A key focus is the elucidation of disease processes and management protocols resulting in improved outcomes for the patient. The manuscript management system is completely online and includes a very quick and fair peer-review system. Visit http://www.dovepress.com/ testimonials.php to read real quotes from published authors. 